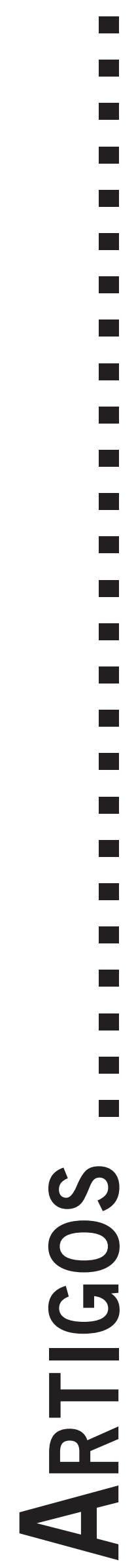




\title{
GESTALT-TERAPIA E FÍSICA QUÂNTICA: UM DIÁLOGO POSSÍVEL¹
}

\author{
Gestalt-therapy and Quantum Physics: a Possible Dialogue \\ Terapia Gestalt y Física Cuántica: un Dialogo Possible
}

Kamila Nogueira Gabriel De Nadai

Adriano Pereira Jardim

\begin{abstract}
Resumo: Este estudo contempla uma discussão epistemológica sobre a psicologia clássica e uma de suas vertentes atuais, a Gestalt-terapia, utilizando-se a trajetória da Física Clássica para a Quântica como pano de fundo. Realizou-se uma discussão por meio de uma revisão bibliográfica, abordando três pontos dicotômicos que envolveram (e ainda envolvem na atualidade) uma transição parcial da Física Clássica para a Física Quântica (linearidade versus não linearidade; ação e reação versus complexidade; e mecânica clássica versus mecânica quântica); e, ilustrativamente, três pontos de discussão associados às Físicas clássicas em contraposição à Gestalt-terapia (causalidade versus existencialismo; elementarismo versus holismo; e objetividade versus fenomenologia). Concluiu-se que existem diferenças e semelhanças nas trajetórias analisadas, como as propriedades paradoxais de seus objetos, o quantum e a consciência humana, configurando pontos de contato que possibilitam um diálogo entre ambas, Física Quântica e Gestalt-terapia.
\end{abstract}

Palavras-chave: Gestalt-terapia; Física Quântica; Desenvolvimento Científico.

\begin{abstract}
This study offers an epistemological discussion about the classic psychology and one of its present components, Gestalt therapy, using the trajectory of classical physics to quantum as a backdrop. There was a discussion through a review by addressing three points involving dichotomous (and still currently involved) a partial transition from classical physics to quantum physics (linearity versus nonlinearity; action and reaction versus complex; and classical mechanics versus quantum mechanics) and, illustratively, three points of discussion related to classical psychology as opposed to Gestalt therapy (causal versus existentialism; elementarism versus holism, and objectivity versus phenomenology). It was concluded that there are differences and similarities in the trajectories analyzed, as the paradoxical properties of its objects, the quantum and human consciousness, setting up contact points that enable a dialogue between both quantum physics and Gestalt-therapy.
\end{abstract}

Keywords: Gestalt Therapy; Quantum Physics; Scientific Development.

Resumen: Este estudio ofrece una discusión epistemológica acerca de la psicología clásica y uno de sus capítulos, la terapia Gestalt, con la trayectoria de la física cuántica clásica como telón de fondo. Hubo una discusión a través de una revisión por resolución de los tres puntos la participación dicotómicos (y sigan operando actualmente) una transición parcial de la física clásica a la física cuántica (la acción linealidad versus la no linealidad; acción y reacción versus complejo; y la mecánica clásica versus la mecánica cuántica) y, ilustrativa, tres puntos de debate relacionados con la psicología clásica en oposición a la terapia Gestalt (causal contra el existencialismo; elementarismo versus holismo, y la objetividad frente a la fenomenología). Se concluyó que hay diferencias y similitudes en las trayectorias analizadas, como las propiedades paradójicas de sus objetos, la cuántica y la conciencia humana, la creación de puntos de contacto que permitan un diálogo entre la física cuántica y la Terapia Gestalt. Palabras-clave: Terapia Gestalt; la Física Cuántica; el Desarrollo Científico.

\begin{abstract}
“(...) Procuramos newtonianamente causas e efeitos, precisamos de segurança, mas a realidade acontece sem obedecer a uma ordem necessária;

antes, as coisas, os processos acontecem em todas as direções. Temos, portanto, de entender que, mesmo tendo escolhido o que pensamos ser o melhor caminho, as possibilidades perdidas continuam ao infinito."
\end{abstract}

(Ribeiro, 1994)

\footnotetext{
1 Artigo produto de trabalho apresentado como requisito para a conclusão do curso de graduação em Psicologia pela Faculdade Brasileira (Univix), Vitória, ES.
}

\section{Introdução}

Atualmente, diversas áreas vêm demonstrando interesse sobre as discussões elaboradas pela Física atual, uma vez que essa teoria apresenta uma possibilidade de desenvolvimento de novas interpretações teóricas e novos conceitos. A Psicologia também busca dialogar com as novas descobertas que envolvem o ser humano em sua relação com o mundo físico. Este artigo apresenta uma discussão entre a Física quântica e a Gestalt-terapia, a partir de suas raízes científicas, as psicologias clássicas e a Física clássica. Para tanto, enfocam-se as implicações das mudanças de concepção sobre o homem para ambos os campos, a partir dos debates da Física e da Psicologia. Na Física, a 
transição do modelo clássico para o modelo quântico tem envolvido uma revisão de conceitos como: o espaço-tempo, a linearidade, a ação e reação e a mecânica clássica; que compuseram novos tópicos como a não-linearidade, o novo conceito espaço-tempo, a imprevisibilidade e a mecânica quântica. Na Física, este trabalho propõe uma narrativa segundo a qual o denominado modelo clássico se desenvolve de forma que a concepção centrada nos conceitos de causalidade linear, elementarismo, objetividade e experiência objetiva de espaço e tempo passam a ser vistos como complexidade, especificação do dado sensorial, valorização da experiência subjetiva, e temporalidade e espacialidade como condições experienciais. Embora a Gestalt-terapia não tenha sido a única teoria psicológica que incorporou tais princípios, entende-se que ela compôs o conjunto mais aproximado do que representou o debate conceitual na Física. A partir dessa concepção, ambos os campos, Física e Psicologia, passaram (e têm passado) por modificações profundas, que implicaram discussões de reposicionamento epistemológico (quanto ao entendimento do funcionamento da consciência na experiência do mundo), metodológico (quanto às formas de pesquisar o mundo) e ontológico (quanto à forma de conceituar o seu objeto - mundo ou homem).

Este trabalho centra na discussão sobre os conceitos envolvidos na transição descrita, a partir de três capítulos. O primeiro discute o caminho percorrido pela Física clássica para chegar às novas teorias na Física quântica. O segundo discute uma compreensão da passagem das aqui denominadas "psicologias tradicionais" até sua chegada na Gestalt-terapia. E o terceiro explora os pontos de contato entre os campos descritos nos capítulos anteriores.

\section{Da Física Clássica à Física Quântica}

A Física clássica, na sua concepção original, era uma coleção de diversas teorias de autores que trabalhavam de forma independente. Newton (1643-1727) foi considerado, entre os séculos XVII e XVIII, como o principal pensador da época, estabelecendo diversas leis muito importantes para o desenvolvimento posterior dessa ciência. O pensador contribuiu para as teorias físicas, começando no momento em que passou a se interessar, ainda em seu período acadêmico, pela mecânica da astronomia de Copérnico e Galileo e a ótica de Kepler. A partir dessas bases teóricas, o físico inglês desenvolveu, entre várias outras teses, a Lei da Gravitação Universal, o telescópio e as três leis que explicam a atuação de forças (sendo elas a inércia, a lei da força e da ação e reação).

O pensamento newtoniano estabeleceu que a Física clássica tivesse por base um pensamento determinista, no qual é possível perceber que o tempo, a massa e as distâncias são medidas ponderadas como absolutas, mostrando que as mesmas não dependem de um referencial pre- viamente estabelecido. Seus conceitos serviram de base para a Física por dois séculos e representaram o avanço de uma ciência que estabeleceu grandes conquistas para o conhecimento humano aplicado e teórico. Somente mais tarde outro pesquisador iria revisar os conceitos newtonianos e abalar conceitos da Física clássica. Albert Einstein desenvolveu teorias revolucionárias que serviram de marco para o início da Física moderna, ou Física quântica. Einstein (1879-1955) desenvolveu suas teorias na primeira metade do século vinte. A Física Quântica pode ser considerada como uma parte da ciência moderna desde a década de 1930, quando diversos estudiosos (como Max Planck²) dessa área começaram a ter uma nova visão acerca dos casos clássicos elaborados pelos físicos de séculos passados.

Einstein, no início de sua trajetória, tentou trabalhar a partir das teorias iniciadas por Newton na Física clássica. Ele passou algum tempo do início de sua vida acadêmica procurando entender as leis da Física clássica. Depois de tentar adequar seus resultados aos princípios newtonianos, o físico alemão discordou da teoria que trabalha com o referencial inercial ${ }^{3}$, trazendo a idéia de que todos os referenciais são igualmente importantes, e que não existe um referencial absoluto, ou seja, não existe o tempo absoluto.

A partir desse momento, Einstein passou a se preocupar com toda a base da Física clássica existente até então, encontrando várias brechas na teoria tradicional que não condiziam com seus estudos. Com isso, outros autores, como Planck, Max Born, Max Laue e outros, algum tempo depois, se juntaram a Einstein para iniciar o estudo de uma Física baseada no quantum, a partícula subatômica (Stachel, 2005). Mas foi o trabalho de Einstein que desvinculou a idéia do tempo absoluto na Física moderna. Ele afirmou que o tempo é tão importante para um referencial inerte quanto para outro. Ou seja, a idéia de tempo absoluto não pode ser válida, pois a vivência de um fenômeno $x$ acontece relativamente em $n$ pontos ao mesmo tempo de uma forma igualmente importante.

Além de toda a teoria desenvolvida por Einstein, é interessante pontuar a sua opinião sobre a importância do pensamento filosófico como uma ferramenta que poderia ser utilizada para desenvolver seus trabalhos científicos. Dentre os filósofos que eram julgados mais importantes no momento, Kant foi o que mais teve influencia sobre o pensamento filosófico de Einstein. A partir disso, ele passa a buscar, antes de tudo, compreender o que está sendo teorizado a partir dos seus resultados, compreender seu sentido e descrever aquilo que se apresenta. Logo, a filosofia de Einstein é uma filosofia de consequências, sugerida por problemas científicos do momento.

\footnotetext{
Max Planck (1858 - 1947) contribui com vastos estudos acerca da mecânica quântica (Santos, Alves \& Duarte, 2007).

3 Referencial inercial é um sistema de referência em que corpos livres (sem forças aplicadas) não têm o seu estado de movimento alterado, ou seja: corpos livres não sofrem acelerações quando não há forças sendo exercidas. Tais sistemas ou estão parados (velocidade nula) ou em movimento retilíneo uniforme uns em relação aos outros.
} 
Parece-me impossível afirmar algo a priori, por mínimo que seja, acerca do método pelo qual devemos construir e relacionar conceitos e o modo como os ordenarmos com experiências sensíveis (...) As regras de associação entre conceitos devem ser simplesmente definidas, pois, caso contrário, o conhecimento, no sentido em que o almejamos, seria inatingível. Podese comparar estas regras àquelas de um jogo, regras estas em si arbitrárias, mas que só depois de definidas possibilitam que se jogue. Esta definição de regras, no entanto nunca será definitiva, mas antes só poderá reclamar para si qualquer validade na área na qual estiver sendo aplicada no momento (ou seja, não há categorias finais no sentido estabelecido por Kant). (Einstein conforme citado por Dahmen, 2006, p. 5).

É fundamental ressaltar que, apesar de todas as grandes contribuições de Einstein para o desenvolvimento da Física quântica, até o final de sua vida o cientista ainda tinha novas considerações a serem feitas acerca da teoria e continuou reinventando-a constantemente, sendo sempre crítico e inovador (Dionísio, 2005).

Os pontos desenvolvidos aqui demonstram o início de uma nova compreensão do mundo que cerca o homem. Especificamente, três conceitos, delimitaram essa transição. São eles: linearidade versus não linearidade, ação e reação versus complexidade, e Mecânica clássica versus Mecânica quântica.

\subsection{Linearidade versus Não Linearidade}

Newton estabeleceu como foco de seus trabalhos uma idéia de total linearidade ${ }^{4}$, mostrando que, para ele, a matéria era estática e previsível. Porém, com o passar das décadas e das novas descobertas que iam sendo feitas, a teoria newtoniana foi severamente questionada e sua "objetividade científica” foi aos poucos dando lugar a um novo pensamento (Gobbi, 2002). Os átomos não eram mais vistos como objetos, mas, sim, como tendências. Com a instauração da Física moderna, os estudiosos passaram a pensar na não-linearidade dos fenômenos, que pode ser entendida como estruturas que não apresentam um único sentido, mas sim, diversos caminhos e fins.

Esta nova teoria, trazendo novos conceitos para a Física, passa a ser um foco, sendo estabelecida a partir da teoria sobre os processos não-lineares ${ }^{5}$. Este estudo é feito baseando-se na idéia que, de uma forma mais ob-

\footnotetext{
A linearidade é a característica que um elemento possui de descrever a relação unidimensional entre causa e efeito.

5 Bianchi et all (p. 3) explica que “(...) a não-linearidade é a propriedade do processo de busca usada na construção dos planos e não uma propriedade da representação do mundo. Assim, esta propriedade é importante porque pode facilitar muito o processo de planejamento, uma vez que a decisão sobre o ordenamento de certas ações pode ser postergado até a execução do plano, ou, ao menos, até o ponto onde alguma informação determine em que ordem certas ações, ainda não ordenadas entre si, devam ser ordenadas entre si”.
}

jetiva, existe uma imprevisibilidade na ação, em qualquer momento, em que dois corpos indistinguíveis estão presentes. Ou seja, a ação que envolve dois corpos distintos não pode ser previamente estabelecida, uma vez que seus comportamentos serão sempre imprevisíveis (Quentmeyer, 2002).

Einstein, em torno de 1917, conseguiu estabelecer um vasto trabalho acerca dos sistemas caóticos dentro da Física quântica, porém, esse feito datou de antes da própria teoria quântica em si ter sido finalizada e de muito antes da teoria dos sistemas caóticos ${ }^{6}$ ser aceita no mundo da Física (Aguiar, 2005).

(...) Einstein dá duas contribuições importantes para a compreensão das regras de quantização. A primeira consiste em estendê-las para sistemas não separáveis, desde que esses tivessem tantas constantes de movimento independentes quantos fossem seus graus de liberdade. Atualmente esses sistemas são ditos integráveis. (...) A segunda contribuição de Einstein é simplesmente observar que quando o sistema clássico não possui o número necessário de constantes de movimento (como Poincaré já havia apontado para o problema de três corpos), nem mesmo a sua regra de quantização se aplicaria e não se sabia como proceder para ‘quantizar’ o sistema (Aguiar, 2005, p. 101).

Atualmente, a não-linearidade dos sistemas é incorporada como parte da Física quântica e permite possibilidades de compreensão do mundo com consequências para as mais diversas áreas do pensamento humano.

\subsection{Ação e Reação versus Complexidade}

O segundo ponto abordado neste artigo trata da diferenciação entre o pensamento mecanicista da ação e reação para a complexidade dos sistemas. A lei desenvolvida por Newton, em seus trabalhos experimentais, demonstra que, quando um corpo em repouso entra em contato com outro, irá ocasionar uma igual reação, de mesmo valor, no segundo.

Essa lei compreende que onde existe uma força sendo exercida com um mesmo sentido, mesma magnitude e igual direção para com um respectivo outro, ela estaria gerando uma resposta equivalente. Isso pode demonstrar uma causalidade das ações entre os corpos nessa teoria. Tal princípio, entretanto, não se aplica aos resultados obtidos pelas pesquisas quânticas. $\mathrm{O}$ trabalho dos físicos quânticos resulta na elaboração de uma nova teoria, que se harmoniza com os resultados observados, denominada “teoria da complexidade”. A complexidade é originária de uma escola filosófica que, em sua visão de mundo, tudo é indissociável. A visão obtida do mundo é de

\footnotetext{
6 De acordo com Aguiar (2005) a teoria do caos quântica só se estabeleceu por volta da década de 70 .
} 
que ele é um todo multidisciplinar que se encontra em relação, a todo momento. Dessa forma, a causalidade da ação e reação é questionada, tendo em vista a nova visão totalitária do mundo, que é submetida às mais diferentes interações a cada momento. O contato entre os corpos, no momento em que interagem pode ser entendido, a partir da complexidade, da seguinte forma: "Quando dois objetos se encontram, pode-se estabelecer uma relação entre ambos - a ação mútua se torna mensurável" (Schuster, 2007, p. 466).

O contato entre sistemas não é mais caracterizado como algo que pode ser pré-estabelecido, não é algo que pode ser previsto. Hoje, conta-se com a visão de que a partir do momento que um contato é estabelecido, a reação não pode ser prevista. O leque de respostas pode ser grande ou pequeno, porém não é mais o mesmo. Ou seja, se um sujeito for de encontro a outro, não é possível afirmar que eles irão colidir e a força feita por um será a mesma força contrária feita pelo outro. A teoria causal Newtoniana só pode ser vista como válida em relação a corpos desprovidos de qualquer movimento ou resistência diferente do outro, dessa forma o contato pode ser igual, havendo uma ação e uma reação teoricamente adequada nesse processo.

\subsection{Mecânica Clássica versus Mecânica Quântica}

A partir das diversas teorias desenvolvidas no auge da Física clássica, é fundamental entender a transição da visão objetiva dos fatos para uma visão complexa atual. Essa visão pode ser elucidada a partir da Mecânica clássica e do princípio da incerteza de Heisenberg ${ }^{7}$ na Mecânica quântica.

A Mecânica clássica newtoniana busca as leis de força, que determinam a atuação de energias sobre as partículas em específicas situações, por meio de seu objeto, da objetividade e da realidade apresentada (Videira, 2008). Partindo da concepção newtoniana, na Física clássica é possível entender que se o cientista conhecer todas as partículas componentes de um sistema, desde sua disposição primária quanto sua massa e velocidade, podem-se avaliar as influências mútuas existentes e antecipar como irão se comportar. Tal lógica só pode ser tomada como verdadeira caso todas as interações sejam descritas com a mais completa precisão, ou seja, desde que o momento e a posição completa das partículas sejam conhecidas (Santos, Alves \& Duarte, 2007).

Em contrapartida, a Mecânica quântica aborda a matéria e a energia a partir de escalas atômicas e subatômicas, tendo implicações diretas a situações de muito baixa ou de muito alta energia. A partir dessa teoria, é fundamental destacar o princípio da incerteza, no qual

\footnotetext{
Werner Heisenberg, físico alemão ganhador do prêmio Nobel da Física no ano de 1932, nasceu em 1901 e faleceu em 1976 (Nunes, 2007).
}

fica explicitado que não é possível distinguir com exatidão a disposição ou o momento da partícula. Isso só seria possível com a alteração da mesma, modificando sua natureza e, consequentemente, o resultado mais fidedigno desejado (Santos et al, 2007). Entretanto, apesar de na Mecânica quântica a maior parte dos eventos importantes envolverem sistemas microscópicos, suas consequências particulares não são apenas compreensíveis nesta escala (Heisenberg, 1949).

A relatividade de Einstein e a Mecânica quântica revolucionaram a maneira com que percebemos o universo e nosso papel na teia viva da criação. Toda a complexidade que vemos no mundo pode surgir do acaso, conforme previsto pela teoria quântica, enquanto nas escalas astronômicas, a própria evolução do universo pode ser descrita a partir de condições iniciais (Abdalla, 2005, p. 148).

Uma vez estabelecida e com seus conceitos desenvolvidos, consolidados e comprovados experimentalmente, esta teoria estabeleceu-se na sociedade física por conta de seu dinamismo e capacidade de lidar com possibilidades. Atualmente, muito ainda há que se discutir para que a complexidade dos sistemas não-lineares seja completamente compreendida. No entanto, é indiscutível a sua contribuição para a compreensão do mundo das partículas e, por extensão, do mundo visível que habitamos. Além disso, é fundamental entender que as evoluções da Física moderna não descartam os esclarecimentos da Física clássica (Videira, 2008).

\section{Das Psicologias Clássicas à Gestalt-terapia}

Conforme previamente citado, o conhecimento psicológico é um dos campos de saber que vem se familiarizando com alguns pensamentos ligados à Física, por isso entende-se ser importante desenvolver de forma epistemológica esta conexão, abrindo mais ainda o leque do pensamento psicológico para explorar as possibilidades que outras áreas podem oferecer para o crescimento da Física.

Tendo isso em vista, é fato que a Física, como é conhecida hoje, não é a mesma de seus primórdios. Assim como qualquer campo do conhecimento humano, ela segue uma linha de desenvolvimento, sendo uma expressão do tempo e das limitações da sua época. Assim sendo, é importante entender o que embasava a Física quando de seu surgimento e o caminho percorrido para seu encontro com a Gestalt-terapia (Figueiredo, 1991).

A Física clássica é estabelecida a partir da visão do estruturalismo de Wilhelm Wundt (1832-1920). Este pensador desenvolveu uma teoria centralista, conhecida como "Física experimental” (Figueiredo, 1991; Schultz \& Schultz, 2009; Marx \& Hillix, 1973). Tal Física trabalha 
com o conceito de causalidade psíquica, que diz respeito "à experiência da conexão de processos psíquicos e ao significado e valor dessa experiência” (Abib, 2005, p. 56). A teoria demonstra que as experiências estão, de alguma forma, conectadas. Ou seja, um pensamento poderia estar sujeito a outro pensamento, assim como um sentimento estaria sujeito a tal pensamento. As ações seriam, dessa forma, diretamente conectadas e causais. Porém, a causalidade que é trabalhada aqui não é proveniente da causalidade física ou da biológica. $\mathrm{O}$ acontecimento da causalidade psíquica é algo imediato e está sujeito a algo subjetivo ou ao indivíduo que a experiencia. Ou seja, "um fenômeno psicológico deve ser explicado com causas psicológicas” (Abib, 2005, p. 56).

Wundt (1917), por exemplo, afirma a liberdade do indivíduo, mas aceita - não enxergando nisto a menor sombra de contradição - que esta mesma liberdade seja "causada", possuindo, portanto, pelo menos algum grau de determinação, ainda que a mesma não seja tão facilmente notável como a causalidade mecânica. Este autor, inclusive, pensa a liberdade como o uso deliberado das nossas ações (Schmidt et al, 2008, p. 11).

A teoria da causalidade psíquica, desenvolvida por Wundt, recebeu duras críticas, desde suas primeiras publicações. Sua psicologia centralista concordava com o dualismo científico ou com a impossibilidade de se reduzir questões da ciência em questões da natureza (Abib, 2005). Wundt desenvolveu, então, a Física experimental, no século XIX, com seu laboratório em Leipzig, que visava, novamente, a consciência imediata do sujeito (Gomes, 1997). Esse feito transformou-o em referência no campo da Física como o fundador da Física experimental. Apesar disso, Wundt acreditava em que uma investigação do campo psicológico não poderia ser reduzida a seu laboratório. Ele entendia a importância de uma visão experiencial e social (Honda, 2004).

Wundt estabeleceu a Física experimental como base para os estudos subsequentes em Física, mas diversos princípios em suas pesquisas foram reformulados, como a metodologia introspectiva. Entretanto, diversas correntes posteriores mantiveram importantes bases epistemológicas que a Física experimental tomou das ciências naturais. O funcionalismo (de John Dewey, William James e James Angell), por exemplo, manteve a visão experimental a partir da observação (Dewey, 1971; James, 1943; Angell, 1907). A psicanálise (na concepção de Freud, 1975) sustentou a noção de causalidade tomada do funcionalismo e da teoria da evolução. E o behaviorismo watsoniano conserva o mecanicismo (Watson, 1970), substituído pelo pensamento funcionalista em Skinner, no behaviorismo radical (Skinner, 1967).

Somente em meados do século vinte iriam surgir outras compreensões teóricas psicológicas, seguindo a rup- tura com os princípios da Física clássica, por meio da Física da forma ou Psicologia da Gestalt, desenvolvida inicialmente por um grupo de profissionais originais da Alemanha que compartilhavam o interesse de pesquisar a percepção (Perls, 1973; Köhler, 1959; Koffka, 1922). Esta preservou a experimentação, mas em bases totalmente novas. A Psicologia da Gestalt tomava o mesmo objeto de Wundt, a consciência, não em seus elementos, mas sim como fenômeno perceptivo submetido a uma totalidade expressiva (muito mais próxima do objeto das ciências pós-românticas, conforme Figueiredo, 1991). A Psicologia da Gestalt serviu de base para as elaborações de Fritz Perls, que compôs o seu pensamento por meio do desenvolvimento da Gestalt-terapia (Perls, Hefferline \& Goodman, 1997).

Frederick Salomon Perls (1893-1970), um judeu de Berlim é hoje conhecido como o pai da Gestalt-terapia (Burow \& Scherpp, 1985). Sua consolidação ocorreu por volta de 1951 e encontrou seu auge, durante um momento social em 1968, após Perls ter praticado por muitos anos a teoria psicanalítica em diversos países. Buscando novos valores humanistas, evocando a responsabilidade e valorizando o ser em relação ao ter, a Gestalt-terapia é uma teoria que trata de diversos fenômenos que dizem respeito ao homem em contato constante com o mundo à sua volta. Mais especificamente, Perls tomou da Psicologia da Gestalt, desenvolvida em meados da década de 1920 por diversos pensadores, como Max Wertheimer, Wolfgang Kohler, Kurt Koffka, Kurt Lewin e Wolfgang Metzger, alguns de seus pressupostos básicos, como a teoria de figura-fundo, todo e partes, e lei da semelhança (Burow \& Scherpp, 1985).

Conforme os teóricos da Gestalt-terapia (Fritz Perls, Laura Perls, Paul Goodman, entre outros) a realidade se mostra, a cada momento e para cada um de nós, de forma singular, assim como todas as coisas (Burow \& Scherpp, 1985). Esse estilo teórico preocupa-se com o 'como' dos fenômenos que são apresentados para cada um, como eles são compreendidos e como a awareness $^{8}$ é feita. Ou seja, o foco da Gestalt-terapia é o ‘como’ das coisas e não o ‘por que’ (Ginger, 2007). Por fim, é interessante ressaltar que os conceitos da Gestalt-terapia são todos complementares e se fundamentam a partir uns dos outros.

O caminho traçado entre a Física clássica e a Física da Gestalt-terapia foi feito a partir de um desenvolvimento teórico. Este encontro se caracterizou particularmente por discussões envolvendo alguns conceitos. Entre estes, destacam-se três: causalidade versus existencialismo, elementarismo versus holismo, e objetividade versus fenomenologia.

\footnotetext{
Estar em contato com a consciência totalmente no momento que se encontra presente, é ter atenção ao que se sente em seu corpo e suas emoções. É entrar em contato com aquilo que mostra, tanto no nível sensorial quanto no intelectual. (Ribeiro, 2006).
} 


\subsection{Causalidade versus Existencialismo}

Com o intuito de explicar os experimentos realizados com base em sua teoria, Wundt trabalhava com a causalidade linear dos fatos. Essa foi a forma que o pesquisador encontrou para poder explorar a origem das questões que se faziam presentes em seus estudos. Sendo assim, ele encontra, de fato, uma significante eficácia em tal instrumento que se mostra suficientemente qualificado para atingir o seu objetivo: a descrição da consciência em seus elementos. A causalidade linear auxiliou-o a garantir o encontro com um grande conhecimento em relação ao objeto de estudo, uma vez que era isolado o fator que era considerado inconstante e inferia os outros pontos como constantes (Czeresnia \& Albuquerque, 1995). Os fatos que eram focados durante o experimento tinham uma conexão linear com outros fatos ( $a$ influencia o comportamento de $b$ que modifica $c$ ). Os fatos são "limpos" (colocados em foco sem a influência de outros pontos externos que podem modificar o resultado de $c$ ). Ressalta-se aqui que, apesar de ser uma teoria fechada, a causalidade ainda é considerada como "efeitos de causas em indivíduos (unidades) específicos que (...) ocorrem na singularidade" (Czeresnia \& Albuquerque, 1995, p. 417). Porém ela não pode ser vista como a única alternativa de estudo para a explicação dos fenômenos.

Em contrapartida à causalidade linear na Física clássica, a Gestalt-terapia se aproxima de outra noção causal a fim de dar conta das práticas em Física: a causalidade circular. Nesta, o macro é considerado como de grande relevância para o desenvolvimento dos processos micro. Diferentemente da causalidade linear, o estudo circular é feito em relação à interação existente nos processos macroscópicos com os microscópicos e não em um só dos pontos do comportamento de um sujeito em relação linear com algo (Haselager \& Gonzalez, 2002). A circularidade complexa tem sua expressão máxima nas formulações do existencialismo (especialmente de Kierkegaard, de Heidegger e de Nietzsche, particularmente influentes no pensamento de Perls). Para além do desenvolvimento dessas teorias, percebe-se que o existencialismo, tomado a partir do pensamento de Perls, aparece como uma fuga da causalidade seja ela circular ou linear, e uma tentativa de compreender as coisas em uma perspectiva completamente original, como uma produção única a cada momento, no aqui - agora. Isto porque as coisas não estão soltas no espaço, mas acontecendo no tempo, o tempo é fundamental para a existência do homem com seu amplo leque de probabilidades (Josgrilberg, 2007).

Ribeiro (1985) então explica que a existência humana se dá pela singularidade e subjetividade dos atos do homem em seu meio. O que remete à ligação deste com a consciência, uma vez que ela está sempre ligada a um objeto e o objeto sempre ligado a ela. Neste raciocínio, o nosso consciente está sempre ligado com o que queremos fazer de nossa existência, sendo isso bom ou ruim para nós mesmos. Porém, mesmo essas decisões subjetivas, conscientes e inconscientes, devem ser vistas como únicas, e de exclusiva responsabilidade do próprio homem. Assim, percebe-se que o homem é o seu próprio ser. Ele deve se responsabilizar por essa existência, que só é percebida de fato a partir de sua relação direta com o mundo. Logo, Ribeiro (1985, p. 35) diz que "o existencialismo tenta e procura o valor e significado do homem. O homem é e deveria ser a grande preocupação do homem". É possível, assim, entender o existencialismo como a forma que o homem escolhe para poder experimentar o seu caminho, como ele o assume, orienta e dirige.

\subsection{Elementarismo versus Holismo}

O elementarismo é uma das formulações teóricas mais importantes para a Física clássica. Segundo Bock, Furtado \& Teixeira (2002), a divisão da psique em elementos aponta para uma compreensão de questões estruturais, ou seja, um estudo sobre as condições rudimentares (ou elementares) da consciência vistas como composições do sistema nervoso central. Essa visão pode ser classificada como um tipo de reducionismo (entendido aqui na perspectiva de Dilthey, conforme Amaral, 2004) utilizado para explicar as partes que se apresentam atreladas ao comportamento humano a partir do funcionamento unitário de um sistema particular. A idéia de alguns dos psicólogos que aderem à teoria clássica de Wundt, como Titchener (1867-1927), é a de que seria melhor iniciar a compreensão do sujeito por meio do que é elementar, a saber, os elementos que vêm a dividir o todo (Engelmann, 2002). Dessa forma, as partes são maiores e mais importantes que o todo. A compreensão sobre o que se passa em uma das partes seria o suficiente para se entender algo específico (como buscar entender o tom de voz usado por uma pessoa e focar o motivo em suas cordas vocais). A compreensão de tais elementos é comumente feita utilizando de experimentos (como os de Wundt em Leipzig).

Essa visão foi fundamental para a Física em seus primórdios e a Gestalt-terapia não a descarta completamente, mas propõe que se trabalharmos com a produção de significado, perceberemos que trabalhamos com a estrutura total, e não com as partes isoladas. Essa forma de visualizar o todo é chamada de holismo, na Gestalt-terapia (Oliveira, 2000).

Segundo Goerdt (1974), o holismo teve seu significado popularizado por Smuts ${ }^{9}$ em 1926 e, a partir dessa época, seu significado passou a ser utilizado de forma generalizada. Nessa idéia, na qual não cabiam experimentos iso-

\footnotetext{
9 Jan Christian Smuts (1870 - 1950) foi um proeminente estadista e soldado da África do Sul. Foi primeiro ministro da África do Sul de 1919 a 1924 e de 1939 a 1948. Era também um advogado e intelectual. Escreveu o livro "Holism and Evolution" em 1926, que deu origem ao termo Holismo (Barrera, 2007).
} 
lados, uma nova visão empírica toma lugar na comunidade gestáltica. $\mathrm{O}$ organismo é visto como algo uno, que não tem como ser dividido por completo em partes que explicarão seu funcionamento (Oliveira, 2000). Por isso, na visão do gestalt-terapeuta, é imprescindível que o ser humano seja visto e tratado como um todo que representa muito mais do que a soma de suas partes, lugar onde tudo está interligado e em que uma parte não consegue existir sem o todo, sendo a recíproca verdadeira. É o eu como um todo fazendo parte do mundo e, mais uma vez, entendendo sua própria responsabilidade perante essa idéia, perante o mundo que também faz parte do sujeito. Isto é, a compreensão de todos os fenômenos que estão à nossa volta, sem nunca nos esquecermos daquilo que está mesmo no fundo, fora de foco, mas que é parte fundamental da sustentação do caminho do homem. No holismo, todos os fenômenos estão ligados a todo o campo ${ }^{10}$ que está à nossa volta.

\subsection{Objetividade versus Fenomenologia}

Para que a instauração da objetividade tomasse seu lugar em seus experimentos, Wundt, inicialmente introduziu a compreensão da consciência como seu objeto de estudo, empregando a introspecção como ferramenta fundamental. No intuito de entender a experiência imediata, além da introspecção, Wundt passou a utilizar aparelhos de laboratórios da área de fisiologia, acreditando ser fundamental estudar a fisiologia determinística dos pontos elementares da esfera mental (Cardoso \& Lopes, 2008). Com isso, é possível entender que uma prática objetiva se fazia indispensável para a execução de sua Física. Wundt procurava objetivar as partes mais elementares da consciência, promovendo a possibilidade do estudo de cada uma das partes da forma mais objetiva possível. Tal feito seria possível a partir da verificação das sensações envolvidas durante o estudo, mesclando assim a introspecção e a objetividade (Cardoso \& Lopes, 2008).

A consequência dessa forma de pensar é que os experimentos utilizados por Wundt eram focalizados na objetividade em prol dos resultados a serem alcançados. É visível que a objetivação de suas técnicas foi fundamental para que o empirismo psicológico alcançasse um novo patamar. Wundt encontra no seu método experimental o controle necessário para ser objetivo (o pesquisador retirava qualquer fator que não interessasse ao resultado para focar na resposta desejada). Isto o levou a ser muito criticado pela Física do século vinte, embora autores posteriores como Titchener, William James e Skinner tenham considerado alguma forma de objetividade como um elemento válido para os experimentos empíricos.

\footnotetext{
${ }^{10}$ Teoria desenvolvida por Kurt Lewin, traz a idéia de que o comportamento humano se dá sempre dentro de um campo de relações, cercado por fatos e acontecimentos que influenciam o mesmo (Lewin, 1965).
}

Porém, na Física estruturalista clássica, a objetividade supervalorizada tornava a teoria excessivamente artificial e com grande ênfase na análise do sujeito (Marx \& Hillix, 1973).

A linha de pensamento crítico à objetividade faz parte das posições epistemológicas da Gestalt-terapia e diz respeito à importância de um fenômeno percebido em um dado momento na vida do sujeito. Ela trata dos objetos apresentados à atenção consciente do homem, ou seja, aquilo que é foco para a pessoa naquele momento. O fenômeno é aquilo que pode ser entendido e assimilado pela mente do homem (Muller-Granzotto \& MullerGranzotto, 2007). A Gestalt-terapia afirma que é muito importante considerar diversas questões que fazem o sujeito ser o que ele é hoje e aquilo que ele quer ser amanhã. Não pode existir uma cisão entre esse dado e o presente, pois, aqui - agora somos o nosso passado, o nosso presente e nosso futuro, tudo compreendido em um só momento. Por isso, é importante estimular o foco do sujeito para aquilo que se apresenta no momento e o que pode significar. A relação figura-fundo compreendida pelo sujeito configura a sua base fenomenológica e implica uma visão específica de mundo. A consciência busca captar a essência mesma das coisas e, para que isso aconteça, ela procura descrever a experiência do modo como ela acontece e se processa, colocando a realidade entre parênteses, suspendendo todo juízo. Essa é a atitude fenomenológica (Gomes, 1997) e implica compreender o processo consciente como inevitavelmente relativo ao sujeito que percebe, sendo impossível uma experiência totalmente objetiva (ou totalmente subjetiva).

Segundo Ribeiro (2006), quando dizemos fenômeno podemos dizer que o homem em si é um fenômeno. Sem dúvida o mais complexo, aquele em que o manifestar-se da consciência percorre caminhos de difícil acesso, pois o fenômeno homem se revela lentamente. Quanto mais ele se desnuda, mais ele vem, se aproxima de uma determinada luz, mais ele está em contato com a sua realidade, com sua essência. Essência essa resultante da relação entre compreensão e experiência, que se processa no mundo fenomenal. O mundo objetivo, portanto, não é mais do que as suas propriedades que se oferecem para serem compreendidas por um sujeito e só podemos falar dele assim, a partir de uma visão particular. A compreensão objetiva da consciência, tentada por Wundt, como consequência, cede lugar a uma visão fenomenológica de um ponto no sujeito, um território objetivo-subjetivo, isto é, o fenômeno.

\section{A Relação entre a Física Quântica e a Gestalt- Terapia}

As relações existentes entre a Física e a Psicologia não são tão recentes quanto se imagina e com certeza não se limitam, no campo da Física, somente à Gestalt-terapia. 
No entanto, embora Física quântica e Gestalt-terapia constituam elaborações específicas às suas áreas, não configuram necessariamente campos isolados. Há 94 anos, Köhler começou a desenvolver um livro intitulado "Gestalten físicas em repouso e em estado estacionário" (Arnheim, 1998), mostrando seu interesse sobre a importância da união dessas duas teorias. Esse trabalho, quase secular, foi encaminhado para Albert Einstein, que exprimiu uma resposta positiva sobre tal conexão (Ash, 1995). A partir disto, é possível entender que as trajetórias da Física e da Psicologia tiveram alguns pontos de encontro. Não são incomuns propostas de paralelismo psicofísico nos projetos tanto das ciências naturais quanto das ciências históricas (Dilthey, 2002). E aqui já se pode apontar um ponto de contato entre Física quântica e Gestalt-terapia: ambas foram formuladas em contraposição a valores tradicionais referentes a pressupostos epistemológicos rigidamente estabelecidos em defesa de uma visão de mundo específica. Foram, portanto, teorias de ruptura em um dado momento histórico.

Outras semelhanças destacam-se, a partir da análise do paralelo entre seus desenvolvimentos. Pode-se afirmar que tanto a Física quântica pode ser considerada como holística (e por consequência gestaltista) quanto a Gestalt-terapia pode ter uma visão quântica da realidade que nos cerca. Conforme Ribeiro, "no universo quântico nada é premeditado, a realidade é um labirinto móvel e indeterminado de possibilidades" (Ribeiro, 1994). Estamos, dessa forma, para além do pensamento linear e causal de Newton, não nos encontramos em um universo de sistemas e fatos já conhecidos.

Usar Física quântica é entender que Gestalt-terapia não é apenas perceber o indivíduo, mas entender quanticamente que a maior e mais harmônica das Gestalts é o universo que se transforma na grande casa que nos acolhe, nos dá vida, nos faz compreensíveis uns aos outros. Só descobrimos o nosso sentido quando, mergulhamos dessa Gestalt maior, entendemos que tudo, sem exceção, é relação e probabilidades (Ribeiro, 1994, p.78).

A semelhança entre as teorias, conforme ressalta Ciornai (2007), aponta para a importância de abrir o campo no qual os profissionais se encontram. Especificamente sobre a prática gestalt-terapêutica, diversas possibilidades complexas se mostram presentes para além do campo atual dessa atuação. A singularidade e a subjetividade da existência humana são fundamentais para entender a complexidade, seja do mundo, seja do homem, da mesma maneira que, nos termos de Figueiredo (1991), os átomos de consciência são as nossas sensações. Tal complexidade se faz presente a partir do momento que o homem entra em contato com o mundo que o cerca.
Foi pelo canal das aplicações técnicas que a ciência foi obrigada a descer da torre de marfim dos fenômenos puros e a encontrar a complexidade como um dos elementos do mundo moderno, primeiro nas estruturas elaboradas pelo homem, depois na natureza onde ela estava, todavia, tão evidentemente inscrita (Moles, 1971, p. 22).

Tanto para a Física quântica, quanto para a Gestaltterapia, essa complexa conectividade entre as ações executadas constantemente pelo homem não é um simples evento que diz respeito somente a ele. Apesar de ele ter a responsabilidade por tais ações, o resultado delas ou até mesmo de suas idéias podem ter influencias no seu entorno. Como o homem não vive em isolamento, suas ações irão repercutir no mundo e determinar caminhos que nem ele mesmo poderia imaginar. A partir disto, a compreensão da imprevisibilidade quântica na construção social do homem é fundamental para entendermos que a imprevisibilidade é inevitável.

A transitoriedade, portanto, é marca fundamental do mundo físico e humano. Nesse sentido, a Física quântica e a Gestalt-terapia representam a constatação da temporalidade como elemento fundamental para a vida (constatação já realizada precocemente por Bergson, 1988). Além disso, constata-se que, a partir do que foi exposto, a percepção é, para cada um, algo sempre novo, em eterna metamorfose. O que entendemos por algo que vemos hoje pode não ser o mesmo quando vemos novamente amanhã. Assim, "Uma pessoa que vi há cinco anos e que vejo hoje em dia não apresenta quase nenhuma parte igual, pelo menos com relação à sua formação básica: os átomos" (Engelmann, 2002, p. 12). Não existe uma constante certeza no meio gestáltico e nem no mundo visto da perspectiva das partículas quânticas. Existe, na verdade, o momento presente e só isso pode, de fato, existir.

Logo, é possível entender a relação existente entre as duas teorias, a Física quântica e a Gestalt-terapia, como o desenvolvimento de campos teóricos resultantes de uma complexificação de visão de homem (Spangenberg, 2007). Isto explicita que os pontos da Física quântica discutidos neste trabalho podem ser utilizados em práticas gestálticas, em suas mais diversas formas (clínica, grupos, escola...). Como citou Ribeiro (1994), a Física quântica parece tornar mais sólidas as considerações da Gestaltterapia. A recíproca também seria verdadeira, por meio da utilização de algumas prerrogativas psicológicas da Gestalt-terapia como base filosófica para o contínuo desenvolvimento da Física quântica. Cabe aqui ressaltar a possibilidade de conscientizar-se de que as teorias podem se relacionar de forma que uma auxilie a outra para que novas práticas tomem forma, o que implica um enriquecimento mútuo e profícuo, tanto para ciência quanto para a filosofia (Holanda \& Faria, 2005). 


\section{Referências}

Abdalla, E. (2005). Teoria quântica da gravitação: cordas e teoria. Revista Brasileira de Ensino de Física [online], 27(1), 147-155.

Abib, J. A. D. (2005). Prólogo à história da psicologia. Psicologia: Teoria e Pesquisa [online], 21(1), 53-60.

Aguiar, M. A. M. (2005). Einstein e a teoria de caos quântico. Revista Brasileira de Ensino de Física [online], 27(1), 101-102.

Amaral, M. N. C. P. (2004). Dilthey - Conceito de vivência e os limites da compreensão nas ciências do espírito. Trans/ Form/Ação [online], 27(2), 51-73.

Angell, J. R. (1907). The province of functional psychology. Psychological Review [online], 14, 61-91. Disponível em: http://psychclassics.yorku.ca/Angell/functional.htm

Arnheim, R. (1998). Wolfgang Köhler and Gestalt theory. History of psychology, 1(1), 21-6.

Ash, M. G. (1995). Gestalt psychology in German culture, 18901967. Cambridge, UK: Cambridge University Press.

Bergson, H. (1988). Ensaio sobre os dados imediatos da consciência. (J. S. Gama, Trad.). Lisboa: Edições 70 (Trabalho original publicado em 1889).

Bock, A. M. B., Furtado, O., \& Teixeira, M. L. T. (2002). Psicologias: uma introdução ao estudo de psicologia. São Paulo: Saraiva.

Burow, O., \& Scherpp, K. (1985). Gestalt-pedagogia: um caminho para a escola e a educação. São Paulo, Summus.

Cardoso, C. R. D. \& Lopes, E. J. O. (2008). Problema mente-corpo e a naturalização da psicologia (cognitiva): considerações epistemológicas. Anais do XXII Seminário de Iniciação Científica. Uberlândia, Universidade Federal de Uberlândia. Disponível em: http://www.ic-ufu.org/anaisufu2008/PDF/ IC2008-0281.PDF

Ciornai, S. (2007). Gestalt-terapia, paradigmas da contemporaneidade e física quântica: um diálogo necessário. Em Enio Brito Pinto (Org.), Gestalt-Terapia: Encontros (pp. 152-172). São Paulo: Instituto Gestalt de São Paulo.

Czeresnia, D., \& Albuquerque, M.F.M. (1995). Modelos de inferência causal: análise crítica da utilização da estatística na epidemiologia. Revista de Saúde Pública, 29(5), 415-423.

Dahmen, S. R. (2006). Einstein e a Filosofia. Revista Brasileira de Ensino de Física [online], 28(1), 3-7.

Dewey, J. (1971). Experiência e educação. São Paulo: Companhia Editora Nacional.

Dilthey, W. (2002). Psicologia e Compreensão. Lisboa: Edições 70.

Dionísio, P. H. (2005). Albert Einstein e a física quântica. Cadernos Brasileiros de Ensino da Física [online], 28(2), 147164. Disponível em: http://www.fsc.ufsc.br/cbef/port/22-2/ artpdf/a1.pdf
Engelmann, A. (2002). A psicologia da gestalt e a ciência empírica contemporânea. Psicologia: Teoria e Pesquisa [online], 18(1), 1-16.

Figueiredo, L. C. M. (1991). Matrizes do pensamento psicológico. Rio de Janeiro: Vozes.

Freud, S. (1975). Esboço de psicanálise. Rio de Janeiro: Imago.

Ginger, S. (2007). Gestalt: a arte do contato: nova abordagem otimista das relações humanas. Petrópolis: Vozes.

Gobbi, S. L. (2002). Teoria do caos e a abordagem centrada na pessoa: uma possível compreensão do comportamento humano. São Paulo: Vetor.

Gomes, W. B. (1997). A Entrevista Fenomenológica e o Estudo da Experiência Consciente. Psicologia USP [online]. 8(2), 305-336.

Goerdt, W. (1974). Holismus. Em J. Ritter (Org.), Historisches Wörterbuch der Philosophie (Band 3, pp. 1167-1168). Darmstadt: Wissenschaftliche Buchgesellschaft.

Haselager, W. F. G. \& Gonzalez, M. E. Q. (2002). Causalidade circular: uma saída para a oposição internalismo versus externalismo? Manuscrito [online], 25, 217-238. Disponível em: http://www.nici.kun.nl/ haselag/publications/ Manuscrito2002.pdf

Heisenberg, W. (1949). The physical principles of the quantum theory. Toronto: Dover Publications.

Holanda, A. F., \& Faria, N. J. (2005). Gestalt-Terapia e Contemporaneidade: Contribuições para uma construção epistemológica da teoria e da prática gestáltica. Campinas: Livro Pleno.

Honda, H. (2004). Notas sobre a noção de inconsciente em Wundt e Leibniz. Psicologia: Teoria e Pesquisa [online], 20(3), 275-277

James, W. (1943). A filosofia de William James: Seleção de suas obras principais. São Paulo: Companhia Editora Nacional.

Josgrilberg, F. P. (2007). A temporalidade a partir da perspectiva existencial. Revista da Abordagem Gestáltica [online], 13(1), 63-73.

Koffka, K. (1922). Perception: An introduction to the Gestalttheorie. Psychological Bulletin, 19, 531-585. Disponível em:http://psychclassics.yorku.ca/Koffka/Perception/perception.htm

Köhler, W. (1959). Gestalt Psychology Today. American Psychologist, 14, 727-734. Disponível em: http://psychclassics.yorku.ca/Kohler/today.htm

Marx, M. H., \& Hillix, W. A. (1973). Sistemas e teorias em Psicologia. São Paulo: Cultrix.

Moles, A. (1971). A criação científica. São Paulo: Perspectiva.

Muller-Granzotto, M. J. \& Muller-Granzotto, R. L. (2007). Fenomenologia e Gestalt-Terapia. São Paulo: Summus.

Oliveira, C. C. (2000). "Holismo: Aprender e Educar”. Diversidade e Diferença. Porto: Faculdade de Letras, Universidade do Porto. 
Perls, F. (1973). A abordagem gestáltica e testemunha ocular na terapia. Rio de Janeiro: LTC.

Perls, F., Hefferline, R., \& Goodman, P. (1997). Gestalt-Terapia. São Paulo: Summus.

Quentmeyer, T. (2002). Chaos theory, dynamic systems, and fractual geometry. Disponível em: http://library.thinkquest. org/3493/frames/menu1.html

Ribeiro, J. P. (1985). Gestalt-Terapia: refazendo um caminho. São Paulo: Summus.

Ribeiro, J. P. (1994). Gestalt-Terapia: o processo grupal: uma abordagem fenomenológica da teoria de campo e holística. São Paulo: Summus.

Ribeiro, J. P. (2006). Vade-mécum de Gestalt-Terapia: conceitos básicos. São Paulo; Summus.

Santos, B. R., Alves, R. S. \& Duarte, O. C. M. B. (2007). Trabalhos de rede I. UFRJ. Disponível em: http://www.Gestalt-Terapiaa. ufrj.br/grad/07_ 1/quantica/index.html.

Schmidt, A., Monteiro, G. G., Carijó, F., Padilha, K., Almeida, M. C., Starosky, M., Kauffman, N., Machado, R., \& Ferreira, A. A. L. (2008). Entre a autonomia e o controle: o surgimento do indivíduo como condição de possibilidade dos saberes e práticas psicológicas. Fractal: Revista de Psicologia [online], 20(1), 337-338.

Schuster, P. M. (2007). Revolucionário e ainda assim desconhecido! Revista Brasileira de Ensino de Física [online], 29(3), 465-470, São Paulo.

Schultz, S. E., \& Schultz, D. P. (2009). História da Psicologia Moderna. São Paulo: Cengage Learning.

Skinner, B. F. (1967). Ciência e comportamento humano. Brasília: Editora da Universidade de Brasília.

Spangenberg, A. (2007). O contato com o livro Gestalt-Terapia um caminho de volta para casa. Campinas: Livro Pleno.

Stachel, J. (2005). 1905 e tudo o mais. Revista Brasileira de Ensino de Física [online], 27(1), 5-9.

Videira, A. A. P. (2008). Breves considerações sobre o tema: Heisenberg e a história. Filosofia e História da Ciência no Cone Sul: Seleção de trabalhos do $5^{\circ}$ encontro, 8, 63-71.

Watson, J. B. (1970). Behaviorism. New York: Norton Library.

Kamila Nogueira Gabriel De Nadai - Graduanda em Psicologia pela Univix - Faculdade Brasileira, Vitória (ES). Endereço Institucional: UNIVIX Faculdade Brasileira. Rua José Alves, 301. Goibeiras, Vitória, ES. CEP 29.075-080. Email: kamilangdn@gmail.com

Adriano Pereira Jardim - Psicólogo, Mestre e Doutor em Psicologia do Desenvolvimento pela Universidade Federal do Rio Grande do Sul. Professor Adjunto da Univix-Faculdade Brasileira. Endereço Institucional: UNIVIX Faculdade Brasileira. Rua José Alves, 301. Goibeiras, Vitória, ES. CEP 29.075-080. Email: adrianopjardim@yahoo.com.br 